\title{
Real-time temperature calculation and temperature prediction of wet multi-plate clutches
}

\author{
D. Groetsch ${ }^{1}$ (D) K. Voelkel ${ }^{1}$ (D) H. Pflaum ${ }^{1}$ (D) $\cdot$ K. Stahl ${ }^{1}$
}

Received: 12 January 2021 / Accepted: 28 July 2021 / Published online: 25 November 2021

(c) The Author(s) 2021

\begin{abstract}
Many applications of wet multi-plate clutches are within safety-critical areas since malfunction or failure of the clutch is often equivalent to "loss of drive".

The main criterion for the estimation of damage and endurance of wet multi-plate clutches is the temperature on the friction interface. Owing to the thin, rotating geometry of the plates, determination of relevant temperatures in operation mode is almost impossible. State of the art is that there is no general applicable model for real-time estimation of clutch temperatures during operation.

This contribution presents a validated parametric real-time temperature model that is applicable to various use cases and operating conditions. The model enables the calculation of the actual clutch temperature during operation and the prediction of temperature for future shifting operations.

The model is validated by comparing temperature measurements from a component test rig and from the KUPSIM thermal clutch design tool with the developed real-time temperature calculation. The validity of the model for serial parts from industry and automotive applications under various load cases (clutch mode, continuous slip, non-steady slip) is demonstrated. The deviation between measurement and calculation are typically very small $(<5 \mathrm{~K})$. The temperature prediction allows a highly accurate (deviations typically $<5 \mathrm{~K}$ ) conservative prediction of the thermal load for future shifting operations.

The model can thus contribute to the increase of operational safety of wet multi-plate clutches while at the same time facilitating optimal component design by reducing thermal over-dimensioning of clutches.
\end{abstract}

\section{Echtzeit-Temperaturberechnung und Temperaturprädiktion nasslaufender Lamellenkupplungen}

\section{Zusammenfassung}

Nasslaufende Lamellenkupplungen sind oft in sicherheitskritischen Anwendungen zu finden in denen Fehlfunktion oder Ausfall der Kupplung mit „Antriebsverlust“ gleichzusetzen ist.

Maßgebliches Kriterium zur Abschätzung der Schädigung und Lebensdauer von nasslaufenden Lamellenkupplungen ist die Temperatur im Reibkontakt. Aufgrund der dünnen, rotierenden Bauteilgeometrie der Lamellen, ist es beinahe unmöglich die relevanten Temperaturen im Betrieb zu bestimmen. Nach Stand der Technik gibt es zudem kein allgemeingültig anwendbares Modell für die echtzeitfähige Temperaturberechnung von Kupplungen im Betrieb.

D. Groetsch

groetsch@fzg.mw.tum.de

K. Voelkel

voelkel@fzg.mw.tum.de

H. Pflaum

pflaum@fzg.mw.tum.de
K. Stahl

fzg@fzg.mw.tum.de

1 Gear Research Centre (FZG), Technical University of Munich, 85748 Garching, Germany 
Dieser Beitrag stellt ein validiertes parametrisches Echtzeit-Temperaturmodell vor, dass auf verschiedene Anwendungsfälle und Betriebsbedingungen anwendbar ist. Das Modell ermöglicht die Berechnung der vorliegenden Kupplungstemperatur im Betrieb und die Prädiktion der Temperaturen für zukünftige Schaltungen.

Das Modell wurde validiert durch den Vergleich von Berechnungsergebnissen mit Temperaturmessungen an einem Komponentenprüfstand und mit Ergebnissen der thermischen Kupplungssimulation KUPSIM. Die Validierung berücksichtigt Serienbauteile aus Industrie- und Fahrzeuganwendungen bei unterschiedlichen Betriebsbedingungen (Kupplungsbetrieb, Dauerschlupf, Instationärschlupf). Die Abweichung zwischen Messungen und Berechnungen sind typischerweise sehr gering $(<5 \mathrm{~K})$. Die Temperaturprädiktion ermöglicht eine hochgenaue (Abweichungen typischerweise $<5 \mathrm{~K}$ ) konservative Vorhersage der thermischen Belastung in zukünftigen Schaltungen.

Das Modell kann somit zu verbesserter Betriebssicherheit von nasslaufenden Lamellenkupplungen beitragen und erleichtert gleichzeitig die optimale Gestaltung von Komponenten, durch die Reduktion der thermischen Überdimensionierung von Kupplungen.

\section{Introduction}

The service life of and damage to multi-plate clutches is mainly influenced by thermal loads [1-4]. Thermal design and recalculation of clutches is possible with the KUPSIM FVA program in order to estimate thermal load on the clutch under changing operational loads. The calculation models and the results are validated by comparison with test rig results with good agreement [5-7].

In addition to the KUPSIM FVA program, there are other studies dealing with the thermal behavior of wet multi-plate clutches. The emphasis here is usually on a high level of detail and effects such as an investigation of complete threedimensional oil flow and unequal pressure distribution due to thermal stresses. Thus, complex two- and three-dimensional calculation models are created to estimate temperature distribution as accurately as possible (see a.o. [8-16]).

However, the models are computationally intensive and each and every case that can be assumed to occur during operation must be considered and recalculated for dimensioning. The small number of large clutches used in maritime and industrial environments often do not allow extensive functional and durability tests on prototype parts.

Further limitations of the experimental validation with test rig tests can be found in the clutch sizes, with diameters in the range of more than one meter, and the large torques transmitted in maritime transmissions. In the case of vehicle transmissions, a design based on an assumption of the worst-case scenario is associated with over-dimensioning of the clutch, which results in excessive costs as well as increased weight and therefore increased fuel consumption and $\mathrm{CO} 2$ emissions.

It is practically impossible to explicitly consider and calculate all load cases during the design process. To protect the powertrain, continuous monitoring of the clutch temperature and prevention of overloading is essential $[3,17]$.

To enable this monitoring, complex sensor technology can be used. Owing to the thin thicknesses of the plates and the rotation of the components, this is not economi- cally feasible with the required operational reliability. This paper presents a validated real-time temperature simulation that enables calculation of the clutch temperature during operation. Furthermore, the model can predict the temperature rise for the time immediately following shifting processes.

The following literature research focuses on the field of real-time temperature calculations. There are very few published models in this area that allow online calculation during operation.

The first works, which form the basis of today's clutch models, were already published at the beginning of the last century.

Geiger [2] calculates the temperature of a multi-plate clutch using a simple one-dimensional model that is probably real-time capable on today's hardware. He already considered heat conduction to connecting components and also found that the friction interface temperature is an important damage criterion. Furthermore, he defined the coupling condition during friction power input on the friction interface.

Additional works that can be regarded as the basis of this paper and thermal calculation of wet clutches are the experimental and theoretical investigations of Steinhilper [18-22]. Based on the laws of heat conduction, he developed oneand two-dimensional equations for calculating the temperature in multi-plate clutches. Furthermore, he transferred these systems of equations into thermal networks in which, however, no oil cooling could be considered. The thermal networks were transferred into electrical circuit diagrams to perform experimental investigations. The accuracy of the calculation results were confirmed by comparison with experiments. For practical purposes, he found that a one-dimensional consideration is usually sufficient for the thermal design of clutches. Owing to the very different operating conditions and friction materials (e.g. asbestos friction linings) at the time, the focus will now be on current literature in the field of real-time temperature calculations.

The fundamentals of thermal behavior of wet-running clutches are once more theoretically investigated by Zhang using a calculation model [23]. The authors find that in- 
creased pressure leads to shorter switching times at higher temperatures. Besides, the influences of oil viscosity, porosity of the friction lining, surface roughness and the lubricant used on the temperature rise in the friction phase are investigated and evaluated.

Seo et al. [24, 25] developed a simple formula for realtime determination of clutch temperature in an axle drive of a four-wheel drive vehicle. They reduce the clutch to a single thermal mass. The energy supply is modeled as the friction power input, the energy dissipation by a lumped heat transfer coefficient that combines all relevant heat transfer phenomena. The heat transfer coefficient is stored in the form of a map, which is determined on a test rig by varying sliding speed and clutch pressure. This model was validated for one operating point.

G. Chen et al. also worked on the implementation of a virtual temperature sensor for clutches in automotive transmissions [3]. The model should improve shifting quality in online operation, since a strong temperaturedependent friction behavior is assumed. Furthermore, the authors conclude that especially in braking operation, heat dissipation via the teeth of clutch carriers makes a significant contribution to clutch cooling. Their model considers heat dissipation mechanisms through convective cooling by the lubricant by means of a Nusselt correlation. Furthermore, the cooling by evaporation of oil is included in case of high temperatures. It is shown that cooling behavior is difficult to estimate. The model is validated on a test rig and in a vehicle transmission on rapid prototyping hardware and shows a correspondence of the calculated maximum temperatures in the range of $\pm 20 \mathrm{~K}$. One reason for these deviations could be that many constants are needed for the complex modeling of the oil cooling, which are difficult to measure. The model focuses on the application in automotive gearboxes and a patent application has been filed in this regard [26].

A real-time capable temperature calculation by means of a thermal network for dual clutch transmissions was developed by $\mathrm{Wu}$ et al. [17]. The authors conclude from their experimental investigations that the thermal behavior of a clutch should be part of the control strategy. In addition, they show a strong temperature-dependent friction behavior. Their thermal model therefore uses a three-dimensional friction coefficient map (pressure, sliding speed and temperature) when calculating the energy input. The model shows a very good agreement in the field tests (deviations in the range of $1-4 \mathrm{~K})$. Furthermore, it is suggested to protect the clutch against overload with the help of the thermal model. For this purpose, clutch pressure should be reduced automatically when the clutch reaches a temperature of $250^{\circ} \mathrm{C}$.

In summary, it can be stated that there is no published parametric model that has been validated for various ap- plications (automotive and industrial). Moreover, the implemented temperature prediction for subsequent shifting cycles represents an extension of the knowledge about the thermal behavior of wet multi-plate clutches.

\section{Method}

Software was developed in Matlab/Simulink for real-time thermal calculation and temperature prediction of wet multi-plate clutches. The thermal calculation model is based on the KUPSIM FVA program [5-7]. Furthermore, a method for predicting critical temperatures based on possible subsequent events is presented. The validation of the calculation model is carried out by comparison with calculation results of the KUPSIM thermal clutch design program and by means of experimental investigations on the component test rig with parts from serial production of automotive and industrial multi-plate clutches.

\subsection{Mathematical model}

The parametric model for calculating clutch temperatures uses input signals provided by sensors. The real geometry of the clutch is transferred into a thermal network [18]. The analogy between electrical and thermal current fields is used for the calculations.

The heat transfer phenomena within the wet multi-plate clutch is solved with the fundamental heat transfer equation (2a).

$\rho c \frac{\partial T}{\partial t}=\frac{\partial}{\partial x}\left(\lambda \frac{\partial T}{\partial x}\right)+\frac{\partial}{\partial y}\left(\lambda \frac{\partial T}{\partial y}\right)+\frac{\partial}{\partial z}\left(\lambda \frac{\partial T}{\partial z}\right)+\dot{q}$

Fig. 1 shows a friction pairing of a wet multi-plate clutch including the radial connecting components (outer carrier (oc) and inner carrier (ic)). The clutch consists of alternately arranged outer plates (here: steel plates (sp)) and inner plates (here: friction plates (fp)). A friction plate typically consists of a friction lining carrier plate with friction lining (fl) on both sides. The illustration corresponds to the spatial system boundaries used for the temperature calculation model according to equation (2a). The calculation domain considers the typically thermally most severely loaded inner friction pairing (axial middle of the clutch package). Owing to the thermal symmetry, the calculation domain can be reduced again to the consideration of half the plate width.

The right side of Fig. 1 shows the thermal network used for the calculations. A thermal network consists in the transient case of areas with concentrated resistances and capacitances. The calculation area, which is composed of different thermal masses, is therefore discretized in nodes. A node is modeled as thermal capacity. In the thermal-electrical anal- 
Fig. 1 Visualization of the realtime temperature model
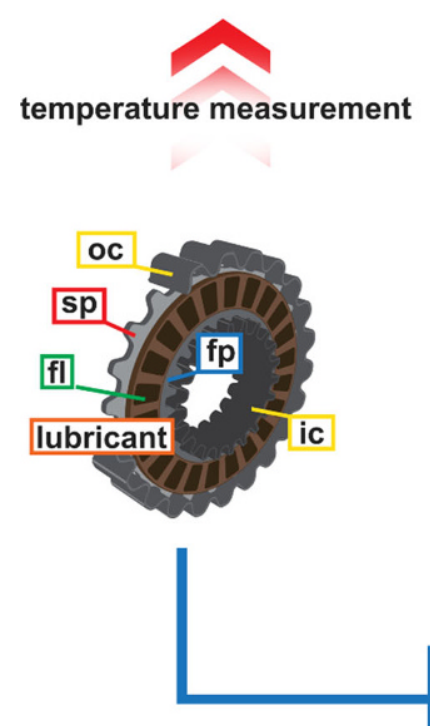

virtual temperature sensor prediction of critical temperatures

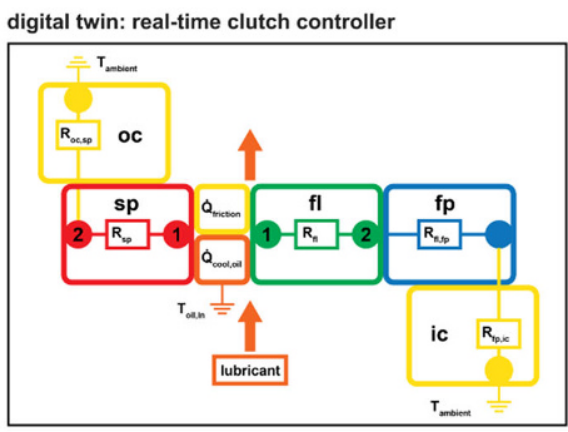

speed torque etc...

parameters

geometry technical data ogy, the temperature of the node corresponds to the voltage at the capacitor. Each node has a temperature T. If there is a temperature difference $\Delta \mathrm{T}$ between two nodes, this results in a compensating heat flow between them. The thermal resistances correspond to the thermal resistances between the thermal masses. These are either convective resistances ( $\left.R_{\text {conv }}\right)$ or thermal resistances due to heat conduction $\left(R_{h c}\right)$. The reference potential of the network is the oil injection temperature or the ambient temperature of the carriers.

The energy input, the heat conduction between the steel plate and the friction lining as well as the heat dissipation due to the cooling oil at the friction surface are taken into account. Energy input and output are implemented in the source/sink terms $\left(\dot{Q}_{\text {friction/cool,oil }}\right)$.

The thermal resistances in Fig. 1 are calculated according to equation ( $2 \mathrm{~b}$ ) for convective heat transfer and according to equation $(2 \mathrm{c})$ for thermal resistances due to heat conduction [27].

$R_{\mathrm{conv}}=\frac{1}{\alpha \cdot A}$

$R_{h c}=\frac{s}{\lambda \cdot A}$

According to equation (2d), the thermal capacities in the thermal network correspond to the product of mass and specific heat capacity [18]. The input parameters for the thermal calculation thus result from the geometry of the calculation domain and the material values of the corresponding material.

$C_{\text {therm }}=\rho \cdot V \cdot c$
The energy input on the friction surface corresponds to the friction work performed per unit of time. It can be assumed that the friction work is completely dissipated as heat [2]. In the real-time temperature model, the friction power is modeled according to equation (2e).

$$
\begin{aligned}
\dot{Q}_{\text {friction }} & =\Delta \omega \cdot T_{f}=2 \pi \cdot \Delta n \cdot T_{f} \\
& =2 \pi \cdot \Delta n \cdot \mu(p, v, T) \cdot F_{a x} \cdot r_{m}
\end{aligned}
$$

The oil cooling (based on the findings of Hämmerl [5]) is taken into account during the sliding phase by balancing the friction power with the effective power according to equation $(2 \mathrm{f})$.

$\dot{Q}_{\text {eff }}=\dot{Q}_{\text {friction }}+\dot{Q}_{\text {cool, lubrciant }}$

The friction partners are in contact with each other. This is considered to be a coupling condition. For this purpose, the effective power supplied according to equation $(2 \mathrm{~g})$ is split into two components in the further calculations. The components are each supplied to the steel plate (sp) or the friction plate (fp).

$\dot{Q}_{\mathrm{eff}}=\dot{Q}_{S P}+\dot{Q}_{F P}$

\subsection{Temperature prediction}

The temperature prediction is implemented using a mapbased approach to reduce the calculation effort. Fig. 2 shows the steps for the commissioning of the prediction module.

First, the real-time temperature model for the desired clutch application must be parameterized. The calculation model should also be validated, for example by compar- 


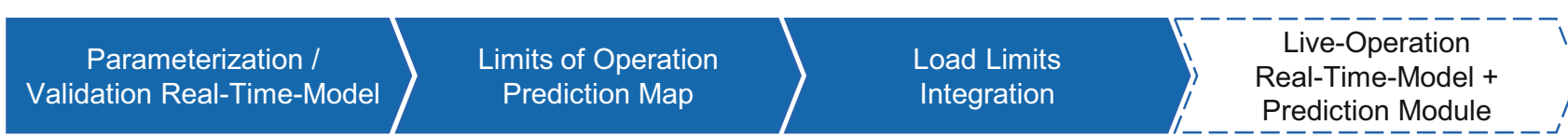

- create input record

- validation e.g. with measured data

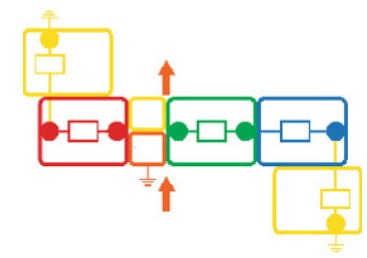

- define limits of operation (speed, torque, feeding oil temperature, ...)

- automated creation and validation of predictive maps

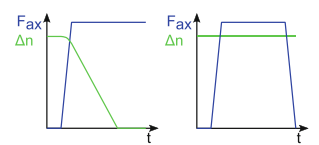

max. permitted steel plate • temperature (clutch, brake, slip mode)

tolerable slip time

integration with simulink

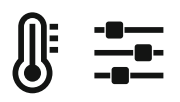

Real-Time-Model: continuous temperature calculation (virtual sensor)

- Prediction Module: Prediction whether thermal load limits are kept

\section{Llll}

Fig. 2 Schematic diagram of how temperature prediction works

ing it with existing measurement data. Next, the operating limits must be defined as min./max. and constant values of the clutch. The specification of the operating limits differs depending on the application, as can be seen from the Table 1.

After the operating limits have been defined, a map for the prediction module can be generated and validated automatically. The resolution of the map can be influenced by specifying the number of interpolation points between the specified operating limits. To create the map, simulations are performed for all parameter combinations using the validated real-time model of the clutch application. Subsequently, the temperature rise (brake operation, clutch operation) or the maximum tolerable slip time (constant slip) is stored for each operating point. Automated validation is carried out by a subsequent comparison of the central points that are not part of the characteristic map with the result of a simulation.

The prediction module can then be made operational by defining the load limits for the maximum permissible steel plate temperature or tolerable slip time and by integrating the previously created map into the Simulink model. In live operation, the thermal behavior of the clutch is provided in the form of a virtual temperature sensor by continuous temperature calculation of the real-time model. By interpolating from the prediction map under the current operating conditions and comparison with the defined load limits, it can be predicted whether the permissible load limits will be kept in the subsequent shifting operation.

\subsection{Experimental investigations}

Extensive measurements for the determination of input variables (speed characteristics, friction coefficient, ...) as well as for the validation of the temperature calculation were carried out on the component test rig ZF/FZG-KLP 260. The design and a classification of the measuring accuracy of the test rig can be found in previous publications [28, 29].

Serial parts of an automotive clutch with carbon fiber friction lining and an industrial clutch with sintered friction lining were used. All investigations were carried out with eight friction interfaces. The steel plates are outer plates and the friction plates are inner plates. The technical data for the two clutches are summarized in Table 2. The data of the lubricants are listed in Table 3.

The temperature of the middle steel plate (axial in the middle of the steel plate/drill hole depth approx. to mean friction radius) was measured with thermocouples ( $\mathrm{NiCrNi}$ Type K Class $1, \varnothing 0.25 / 0.5 \mathrm{~mm}$ ) at several points evenly distributed around the circumference. To determine the mass temperature of the steel plate, the signals of the thermocouples distributed around the circumference are averaged.

All test parts are run-in at the beginning to avoid nonlinear effects which only occur in the initial cycles during the tests. [30, 31].

After running-in, tests were carried out with the BGII clutches in non-steady slip to characterize the temperature behavior under different operating conditions. Fig. 3 shows an example of the course of the differential speed as well as the axial force in non-steady slip.

Here the clutch is first closed by applying an axial force. Then the clutch is accelerated several times cyclically (here within one second) to a maximum differential speed $\Delta \mathrm{n}$ and immediately after reaching this differential speed, it is decelerated again with the same gradient (thus also within one second) to the initial speed of zero. This procedure is repeated several times after a short pause (here five times). After the last deceleration, the clutch is briefly released. In the test sequence, the maximum differential speed, the axial force and the number of cycles are varied. A cooling phase follows to allow the clutch components to cool down. This is defined by a fixed differential speed of $\Delta n=20 \mathrm{rpm}$ and an axial force of $100 \mathrm{~N}$ which is maintained for a defined 
Table 1 Required specifications for the operating limits of the prediction module

\begin{tabular}{|c|c|c|c|}
\hline & $\begin{array}{l}\text { Braking } \\
\text { operation }\end{array}$ & $\begin{array}{l}\text { Clutch } \\
\text { operation }\end{array}$ & $\begin{array}{l}\text { Constant } \\
\text { slip }\end{array}$ \\
\hline Input speed/rpm & $\mathrm{X}$ & $\mathrm{X}$ & $\mathrm{X}$ \\
\hline Output speed/rpm & - & $\mathrm{X}$ & $\mathrm{X}$ \\
\hline Friction torque/Nm & $\mathrm{X}$ & $\mathrm{X}$ & $\mathrm{X}$ \\
\hline $\begin{array}{l}\text { Oil volume } \\
\text { flow } / \mathrm{mm}^{3} / \mathrm{mm}^{2} \mathrm{~s}\end{array}$ & $\mathrm{X}$ & $\mathrm{X}$ & $\mathrm{X}$ \\
\hline $\begin{array}{l}\text { Oil injection tempera- } \\
\text { ture } /{ }^{\circ} \mathrm{C}\end{array}$ & $\mathrm{X}$ & $\mathrm{X}$ & $\mathrm{X}$ \\
\hline $\begin{array}{l}\text { Start temperature } \\
\text { calculation } /{ }^{\circ} \mathrm{C}\end{array}$ & $\mathrm{X}$ & $\mathrm{X}$ & $\mathrm{X}$ \\
\hline $\begin{array}{l}\text { Moment of inertia } \\
\text { drive } / \mathrm{kgm}^{2}\end{array}$ & $\mathrm{X}^{\mathrm{a}}$ & $\mathrm{X}^{\mathrm{a}}$ & - \\
\hline $\begin{array}{l}\text { Moment of inertia } \\
\text { output } / \mathrm{kgm}^{2}\end{array}$ & $X^{a}$ & $\mathrm{X}^{\mathrm{a}}$ & - \\
\hline Drive torque/Nm & $\mathrm{X}^{\mathrm{a}}$ & $\mathrm{X}^{\mathrm{a}}$ & - \\
\hline Output torque/Nm & $\mathrm{X}^{\mathrm{a}}$ & $X^{a}$ & - \\
\hline $\begin{array}{l}\text { Max. steel plate tem- } \\
\text { perature } /{ }^{\circ} \mathrm{C}\end{array}$ & - & - & $\mathrm{X}^{\mathrm{a}}$ \\
\hline Max. simulated time/s & - & - & $\mathrm{X}^{\mathrm{a}}$ \\
\hline
\end{tabular}

${ }^{\text {a }}$ Constant values

time (typically $20 \ldots 30 \mathrm{~s}$ ). The low axial force ensures that the cooling oil in the grooves is distributed around the circumference of the clutch, generating a negligible amount of frictional power.

With the BGIII clutches, tests in constant continuous slip were investigated. Fig. 4 shows an example of a continuous slip test that was used to determine the heat transfer coefficients with KUPSIM according to Wohlleber [6].

Here the differential speed is increased in steps of $10 \mathrm{rpm}$, while the clutch remains closed owing to the applied constant axial force. The clutch is thus permanently in slip operation and there is a continuous input of frictional power which leads to a heating of the components. The speed stages are held until an almost constant steel plate temperature is reached. When an average steel plate temperature of approx. $200^{\circ} \mathrm{C}$ is reached, the tests are stopped in order to prevent damage to the clutch. The clutch pressure is varied between the test runs.
Table 2 Summary of the technical data of the test parts

\begin{tabular}{lll}
\hline $\begin{array}{l}\text { Mean friction ra- } \\
\text { dius/mm }\end{array}$ & Automotive (BGII) & Industry (BGIII) \\
$\begin{array}{l}\text { Number of friction } \\
\text { linings }\end{array}$ & 8 & 61.3 \\
Clearance/mm & 0.2 & 8 \\
Friction lining & $\begin{array}{l}\text { Carbon } \\
\text { Radial multi-seg- } \\
\text { mented }\end{array}$ & Waffle \\
ATF-A & Sinter \\
\hline
\end{tabular}

\section{Results}

The calculations of the real-time model are at first validated using representative load levels for clutch operations in comparison with results of the KUPSIM clutch thermal design program. The calculations are carried out with the same input parameters. Subsequently, a comparison and evaluation of the output parameters are performed. A clutch system is used with which KUPSIM has already been experimentally validated. This procedure ensures that the thermal calculation with KUPSIM is correct. The material and geometric data correspond to an automotive clutch with a mean friction radius of $88.1 \mathrm{~mm}$ with group parallel grooves and a paper friction lining. ATF-B is used as lubricant. All input variables of the calculation were taken from the literature $[6,32]$ The loads of the test consist of four load levels. The load levels are calculated as a load sequence in the order LS1-1-LS3-LS4-LS2-LS1-2. The course of axial force and speed of the load levels can be seen in Fig. 5 .

In the following, the calculation results of the real-time model are compared with the results from KUPSIM under reference conditions. A specific oil volume flow of $0.65 \mathrm{~mm}^{3} / \mathrm{mm}^{2} \mathrm{~s}$ at an oil injection temperature of $80^{\circ} \mathrm{C}$ is defined as reference condition. In KUPSIM, the sliding phase is considered spatially resolved in two dimensions. The cooling phases are calculated spatially isothermal. Fig. 6 shows the temporal course of the calculated temperatures of node $\mathrm{S} 2$ of the real-time model and the isothermal steel plate temperature from KUPSIM.
Fig. 3 Time course of differential speed and axial force in nonsteady slip test BGII

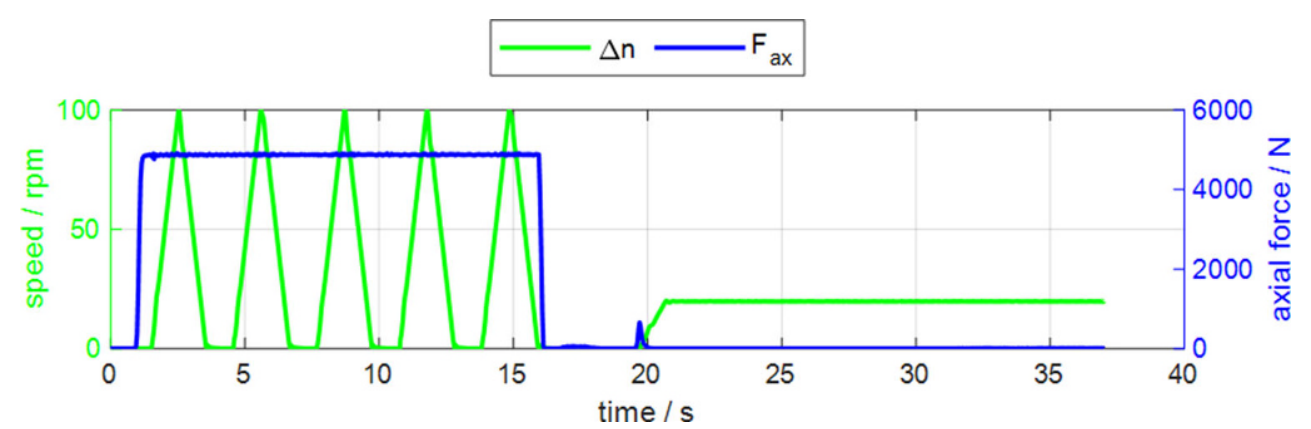


Table 3 Data of the lubricants

\begin{tabular}{llll}
\hline & $\begin{array}{l}\text { Kin. visc. } \\
40^{\circ} \mathrm{C} / \mathrm{mm}^{2} / \mathrm{s}\end{array}$ & $\begin{array}{l}\text { Kin. visc. } \\
100^{\circ} \mathrm{C} / \mathrm{mm}^{2} / \mathrm{s}\end{array}$ & $\begin{array}{l}\text { Density } \\
15^{\circ} \mathrm{C} / \mathrm{kg} / \mathrm{m}^{3}\end{array}$ \\
\hline ATF-A & 29.7 & 6.4 & 848 \\
ATF-B & 28 & 12.6 & 760 \\
Industry & 100 & 11.4 & 891 \\
\hline
\end{tabular}

The isothermal steel plate temperature in KUPSIM in the sliding phase (axial force and differential speed is present) is determined by numerical integration over the two dimensional domain of the steel plate. It can be seen that a typical temperature characteristic for wet multi-plate clutches is obtained. This is characterized by a strong heating of the plate during the sliding phase and the subsequent exponential cooling phases. The temperature curve in the cooling phases shows a change in cooling rate in the transition between the closed (axial force applied) and open (no axial force) cooling phase. This can be explained by the changed heat transfer due to the opening of the clutch (oil flow rate, heat transfer coefficient). The S2 node temperature is in very good agreement with the isothermal steel plate temperature from KUPSIM. The spatially two-dimensional calculation of KUPSIM enables the output of the peak temperature at the friction interface for each sliding phase. In Table 4, the local peak and mean peak temperatures of the steel plates from KUPSIM are compared to the peak temperatures of node $\mathrm{S} 2$ with the different load levels. It can be seen that the temperatures in the real-time model follow the calculation in KUPSIM. The differences for the maximum temperatures are due to the one-dimensional modeling. In the real-time model, the heat is distributed to a larger thermal mass per time step. The mean peak temperatures show good agreement (within $\pm 10 \mathrm{~K}$ ).

The cooling in the real-time model is slightly lower compared to the spatial resolved calculation in KUPSIM. The cooling phases in the real-time model would therefore be slightly longer than in KUPSIM until complete recooling. This leads to a slightly higher node temperature in sequential shifting operations with almost the same temperature rise and thus improves the prediction of the local peak temperature.

Fig. 7 shows the comparison of the calculation with the real-time model and a temperature measurement in continuous slip (compare Fig. 4) using the heat transfer coefficient determined according to Wohlleber $\left(\alpha=8000 \mathrm{~W} / \mathrm{m}^{2} \mathrm{~K}\right.$ (sinter)) [6].

The figure of the temperature curves shows very good agreement. This applies to the dynamic change from one speed plateau to the next higher one as well as to the stability of the calculation while one speed step is held constant. The absolute deviations of the temperatures shortly before the rise to the next speed level are summarized in Table 5. The values confirm the optical impression and show an excellent agreement between measurement and simulation.

Fig. 8 shows the comparison of the calculation with the real-time model and a temperature measurement in one nonsteady slip test (see Fig. 3) using the heat transfer coefficient determined according to Wohlleber $\left(\alpha=2100 \mathrm{~W} / \mathrm{m}^{2} \mathrm{~K}\right.$ (carbon)) [6].

Fig. 8 shows that the model also has very good agreement with the measured values in non-steady slip. This is
Fig. 4 Time curve of differential speed and axial force of the continuous slip test BGIII
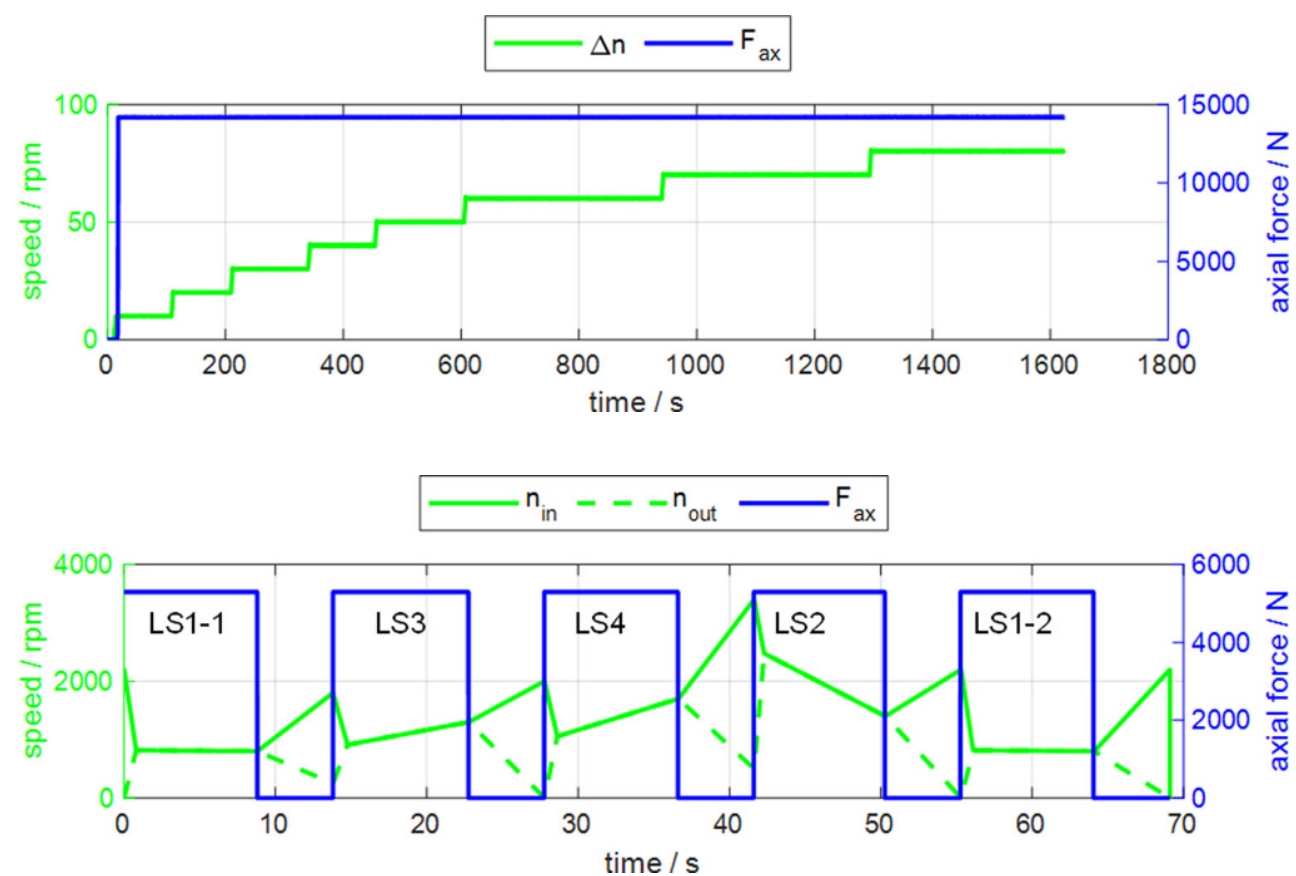

Fig. 5 Time curve of input and output speeds and axial force of load levels LS11-LS3-LS2-LS4-LS1-2 
Fig. 6 Temperature curves of the isothermal steel plate temperature from KUPSIM and the node temperature (S2) of the real-time model for the load levels LS11-LS3-LS4-LS2-LS1-2 $\left(\mathrm{v}_{\mathrm{oil}}=0.65 \mathrm{~mm}^{3} / \mathrm{mm}^{2} \mathrm{~s}\right.$, $\mathrm{T}_{\text {oil, in }}=80^{\circ} \mathrm{C}, p=1.0 \mathrm{~N} / \mathrm{mm}^{2}$, ATF-B)

Fig. 7 Temperature curves of the measured steel plate temperature and the node temperature (S2) of the realtime model in continuous slip $\left(\mathrm{v}_{\text {oil }}=1.0 \mathrm{~mm}^{3} / \mathrm{mm}^{2} \mathrm{~s}\right.$, $\mathrm{T}_{\text {oil,in }}=80^{\circ} \mathrm{C}, p=2.0 \mathrm{~N} / \mathrm{mm}^{2}$, Industry, BGIII)
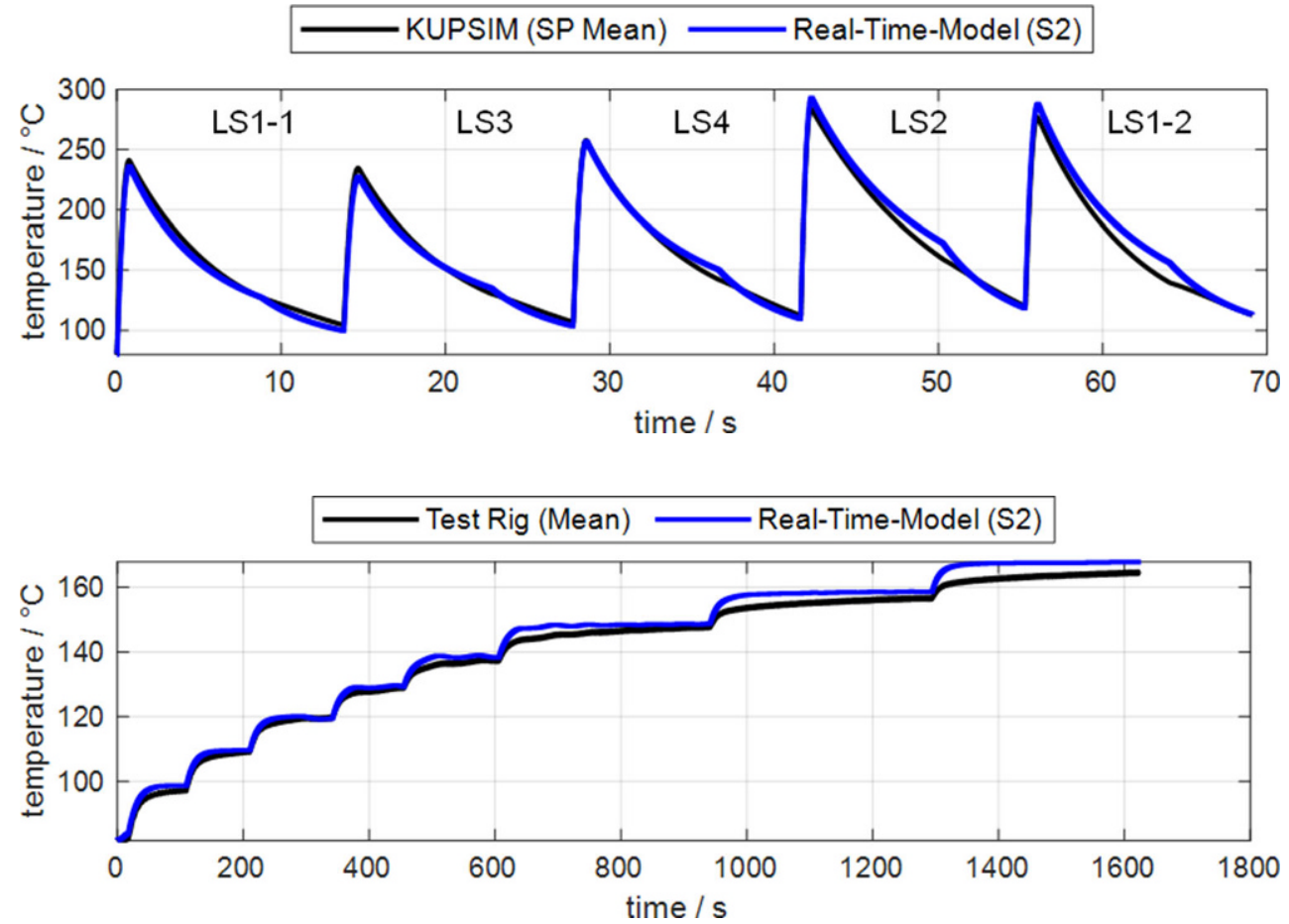

particularly noteworthy since the thermal conditions in the non-steady slip change continuously over the phase of repeated cyclical acceleration and deceleration of the clutch (see Fig. 3). By changing the differential speed with constant axial force, for example, the supplied thermal power varies. Furthermore, the continuous heating of the components influences frictional behavior (and thus the energy input) as well as the cooling power by changing, for example, oil viscosity.

The absolute deviations of the local maximum temperatures (in the range of the maximum differential speeds) are summarized in Table 6. The values also show an excellent agreement between measurement and simulation.

To validate the temperature prediction, the points furthest away are selected between the grids stored in the map. There, the inaccuracy that results from interpolation is the greatest. For all these points, a full simulation is used to calculate the required value. The same value is also generated by interpolation from the map. The deviation of the interpolated values from the simulated values gives information about the accuracy of the prediction module.

Fig. 9 shows the results of the validation for a prediction map with 3125 values (memory requirement approx. $27 \mathrm{kB}$, number of interpolation points $=5$ for all parameters). The operating limits were defined for an automobile clutch with an average friction radius of $58.3 \mathrm{~mm}$. The specific friction work varies in the range of $0.03 \ldots 1.23 \mathrm{~J} / \mathrm{mm}^{2}$, the specific friction power in the range of $0.14 \ldots 4.35 \mathrm{~W} / \mathrm{mm}^{2}$ and the pressure in the range of $0.7 \ldots 3.7 \mathrm{~N} / \mathrm{mm}^{2}$ for a drive inertia of $\mathrm{J}_{\mathrm{in}}=1.25 \mathrm{kgm}^{2}$. There are 1024 test points with the great- est distance from the values stored in the map. The figure shows that the deviations between prediction module and real-time model are in the range of $0 \ldots 4 \mathrm{~K}$. The mean value and the median of the deviations are $3 \mathrm{~K}$. It can furthermore be seen that the prediction is always conservative because it predicts a higher temperature. A high accuracy of the temperature prediction over the given operating range of the clutch is therefore shown.

\section{Conclusion}

The objective of the development of the model was to calculate the thermal behavior of wet multi-plate clutches during operation in real-time by means of an online simulation and to predict the temperatures for possible subsequent operating states.

Based on the findings on the thermal behavior of wet multi-plate clutches from the literature, a real-time capable calculation model was derived. The model can be parame-

Table 4 Comparison of the maximum temperatures per load level of node S2 with the maximum steel plate temperature per load level of the spatially two-dimensionally calculated sliding phase in KUPSIM

\begin{tabular}{llllll}
\hline & LS1-1 & LS3 & LS4 & LS2 & LS1-2 \\
\hline $\mathrm{T}_{\mathrm{SL}, \text { max,KUPSIM }} /{ }^{\circ} \mathrm{C}$ & 258 & 247 & 273 & 306 & 295 \\
$\mathrm{~T}_{\mathrm{SL}, \text { mean,max,KUPSIM }} /{ }^{\circ} \mathrm{C}$ & 241 & 235 & 258 & 284 & 277 \\
$\mathrm{~T}_{\mathrm{SL} \text {,max,real time model }} /{ }^{\circ} \mathrm{C}$ & 236 & 227 & 257 & 293 & 288 \\
$\Delta \mathrm{T}_{\mathrm{SL}, \text { max }} / \mathrm{K}$ & 22 & 20 & 16 & 13 & 7 \\
$\Delta \mathrm{T}_{\mathrm{SL}, \text { mean }} / \mathrm{K}$ & 5 & 8 & 1 & -9 & -9 \\
\hline
\end{tabular}


Fig. 8 Temperature curves of the measured steel plate temperature and the node temperature (S2) of the realtime model in non-steady slip ( $v_{\text {oil }}=0.25 \mathrm{~mm}^{3} / \mathrm{mm}^{2} \mathrm{~s}$, $\mathrm{T}_{\text {oil, in }}=90^{\circ} \mathrm{C}, p=1.0 \mathrm{~N} / \mathrm{mm}^{2}$, ATF-A, BGII)

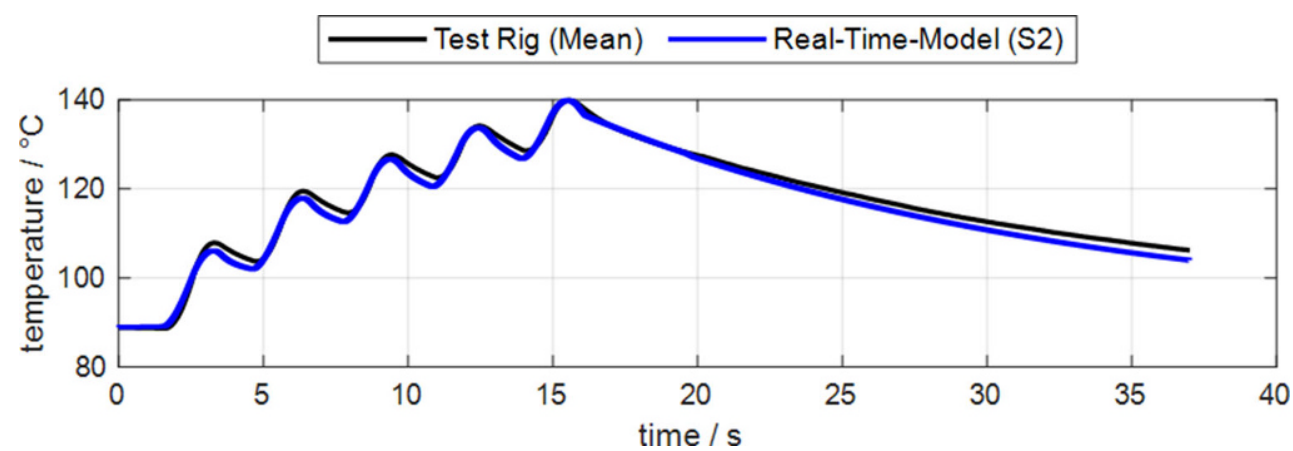

time / s

Table 5 Comparison of the measured mass temperatures on the test rig and the temperatures of node $\mathrm{S} 2$ shortly before the rise to the next speed level in continuous slip

\begin{tabular}{lllllllll}
\hline$\Delta \mathrm{n} / \mathrm{rpm}$ & 10 & 20 & 30 & 40 & 50 & 60 & 70 \\
\hline Time/s & 100 & 200 & 300 & 450 & 600 & 900 & 1250 \\
$\mathrm{~T}_{\mathrm{SL}, \text { measurement }} /{ }^{\circ} \mathrm{C}$ & 97 & 109 & 119 & 129 & 137 & 147 & 156 \\
$\mathrm{~T}_{\mathrm{SL}, \text { real time model }}{ }^{\circ} \mathrm{C}$ & 99 & 109 & 119 & 128 & 139 & 149 & 159 \\
$\Delta \mathrm{T}_{\mathrm{SL}} / \mathrm{K}$ & 2 & 0 & 0 & 1 & 2 & 2 & 3 & 164 \\
\hline
\end{tabular}

Table 6 Comparison of the measured local maximum mass temperatures on the test rig and the node S2 in non-steady slip

\begin{tabular}{llllll}
\hline Local maximum no & 1 & 2 & 3 & 4 & 5 \\
\hline Time/s & 3.3 & 6.3 & 9.3 & 12.4 & 15.4 \\
$\mathrm{~T}_{\mathrm{SL}, \text { max }, \text { local,measurement }} /{ }^{\circ} \mathrm{C}$ & 108 & 119 & 127 & 134 & 140 \\
$\mathrm{~T}_{\mathrm{SL}, \text { max,local,real-time model }} /{ }^{\circ} \mathrm{C}$ & 106 & 117 & 126 & 134 & 140 \\
$\Delta \mathrm{T}_{\mathrm{SL}} / \mathrm{K}$ & 2 & 2 & 1 & 0 & 0 \\
\hline
\end{tabular}

terized and is based on the physical laws of heat transport. This allows a broad application for arbitrary clutch sizes, applications (industry, automotive, maritime), and load scenarios (e.g. clutch/brake mode, continuous slip, non-steady slip) in contrast to approaches known from the literature, which usually focus on a special application (see for example $[3,17])$.

The prediction module distinguishes between critical and non-critical load cases on the basis of definable thermal

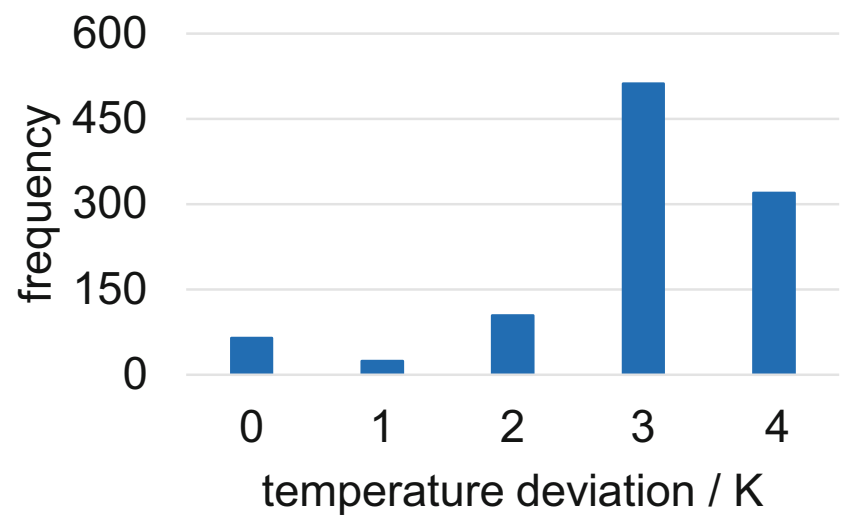

Fig. 9 Histogram of temperature deviation from prediction to simulation (brake mode; map: 1024 test points) load limits of the clutch and represents an extension of the previously known model formation.

The results of the prediction for critical states, such as the continuation of the continuous slip load or specific subsequent load shifts, could be transmitted to the powertrain control system via the output interface. The latter can thus prevent thermal overload of the clutch. Furthermore, a recording of thermal loads of the clutch components is possible, which makes temperature-time components accessible for subsequent statistical evaluation.

The development of the model in Matlab/Simulink enables the integration of the model into existing transmission concepts.

By comparing temperature measurements and real-time temperature calculations, the validity of the model formation for various clutch applications and load cases was demonstrated. The deviation between measurements and calculations are typically very small $(<5 \mathrm{~K})$. The temperature prediction allows a highly accurate (deviations typically $<5 \mathrm{~K}$ ) conservative prediction of the thermal load for future shifting operations.

The model can thus contribute to the increase of operational safety of wet multi-plate clutches, while at the same time ensuring critical component design.

Acknowledgements The presented results are based on the research project FVA no. 413/V; self-financed by the Research Association for Drive Technology e. V. (FVA). The authors would like to thank for the sponsorship and support received from the FVA and the members of the project committee.

Funding Open Access funding enabled and organized by Projekt DEAL.

Open Access This article is licensed under a Creative Commons Attribution 4.0 International License, which permits use, sharing, adapta- 
tion, distribution and reproduction in any medium or format, as long as you give appropriate credit to the original author(s) and the source, provide a link to the Creative Commons licence, and indicate if changes were made. The images or other third party material in this article are included in the article's Creative Commons licence, unless indicated otherwise in a credit line to the material. If material is not included in the article's Creative Commons licence and your intended use is not permitted by statutory regulation or exceeds the permitted use, you will need to obtain permission directly from the copyright holder. To view a copy of this licence, visit http://creativecommons.org/licenses/by/4. $0 /$.

\section{References}

1. Hensel M (2014) Thermische Beanspruchbarkeit und Lebensdauerverhalten von nasslaufenden Lamellenkupplungen. Dissertation. Technische Universität München, München

2. Geiger J (1937) Die Erwärmung von Kupplungen und Bremsen. Automobiltech Z 9(7):34-35

3. Chen G, Baldwin K, Czarnecki E (2011) Real time virtual temperature sensor for transmission clutches vol 4

4. Lingesten N, Marklund P, Höglund E (2017) The influence of repeated high-energy engagements on the permeability of a paper-based wet clutch friction material. Proc Inst Mech Eng Part J 231(12):1574-1582. https://doi.org/10.1177/1350650117700807

5. Hämmerl B (1995) Lebensdauer-und Temperaturverhalten ölgekühlter Lamellenkupplungen bei Lastkollektivbeanspruchung. Dissertation. Technische Universität München, München

6. Wohlleber F (2012) Thermischer Haushalt nasslaufender Lamellenkupplungen. Dissertation. Technische Universität München, München

7. Voelkel K, Wohlleber F, Pflaum H, Stahl K (2018) Kühlverhalten nasslaufender Lamellenkupplungen in neuen Anwendungen. Forsch Ingenieurwes 82:197-203. https://doi.org/10.1007/s10010018-0273-1 (Cooling performance of wet multi-plate disk clutches in modern applications)

8. Karamavruc A, Shi Z, Gunther D (2011) Determination of empirical heat transfer coefficients via CFD to predict the interface temperature of continuously slipping clutches. https://doi.org/10.4271/ 2011-01-0313. https://www.sae.org/publications/technical-papers/ content/2011-01-0313/

9. Jungdon C (2012) A multi-physics model for wet clutch dynamics. Dissertation. The University of Michigan, Michigan

10. Wenbin L, Jianfeng H, Jie F, Liyun C et al (2016) Simulation and application of temperature field of carbon fabric wet clutch during engagement based on finite element analysis. Int Commun Heat Mass Transf 71:180-187. https://doi.org/10.1016/j. icheatmasstransfer.2015.12.026

11. Li L, Li H, Wang L (2017) Numerical analysis of dynamic characteristics of wet friction temperature fields. Adv Mech Eng 9(12):168781401774525. https://doi.org/10.1177/16878140177 45252

12. Park S-M, Kim M-S, Kim J-Y, Lee K-S (2017) The heating and cooling performance analysis of transmission wet clutch with real shape and lubricant condition. In: 16th International CTI Symposium Automotive Transmissions, HEV and EV Drives Berlin

13. Lin T, Tan Z, He Z, Cao H et al (2018) Analysis of influencing factors on transient temperature field of wet clutch friction plate used in marine gearbox. Ind Lubr Tribol 70(2):241-249. https://doi. org/10.1108/ILT-08-2016-0181

14. Mahmud SF, Pahlovy SA, Ogawa M (2018) Simulation to estimate the output torque characteristics and temperature rise of a transmission wet clutch during the engagement process. In: WCX World Congress Experience 10 Apr 2018. SAE Technical Paper Series. SAE, Warrendale
15. Wu W, Xiao B, Yuan S, Hu C (2018) Temperature distributions of an open grooved disk system during engagement. Appl Therm Eng 136:349-355. https://doi.org/10.1016/j.applthermaleng.2018. 03.016

16. Yu L, Ma B, Li H, Liu J et al (2019) Numerical and experimental studies of a wet multidisc clutch on temperature and stress fields excited by the concentrated load. Tribol Trans 62(1):8-21. https:// doi.org/10.1080/10402004.2018.1453570

17. Wu J, Ma B, Li H, Liu J (2019) Creeping control strategy for Direct Shift Gearbox based on the investigation of temperature variation of the wet multi-plate clutch. Proc Inst Mech Eng Part D 233(14):3857-3870. https://doi.org/10.1177/0954407019836313

18. Steinhilper W (1962) Der zeitliche Temperaturverlauf in Reibungsbremsen und Reibungskupplungen beim Schaltvorgang. Karlsruhe, Techn. Hochsch., Diss.. Berenz, Karlsruhe

19. Steinhilper W (1963) Der zeitliche Temperaturverlauf in schnellgeschalteten Reibungskupplungen und -bremsen: Teil 2. Automobiltech Z 65(10):326-329

20. Steinhilper W (1964) Ermittlung des Temperaturverlaufs in Reibungsbremsen und -kupplungen mit Hilfe eines Analogieverfahrens. Automobiltech Z 66(8):228-371

21. Steinhilper W (1963) Der zeitliche Temperaturverlauf in schnellgeschalteten Reibungskupplungen und -bremsen: Teil 1. Automobiltech Z 65(8):223-229

22. Steinhilper W (1963) Temperatuverlauf in Lamellenkupplungen beim Schaltvorgang. VDI Ber 73:89-104

23. Zhigang Z, Xiaohui S, Dong G (2016) Dynamic temperature rise mechanism and some controlling factors of wet clutch engagement. Math Probl Eng 2:1-12. https://doi.org/10.1155/2016/6530213

24. Seo H, Cha SW, Lim W, Han S (2015) Method for estimating temperature of 4WD coupling device wet clutches in severe operating condition. Int J Precis Eng Manuf 16(1):185-190. https://doi.org/ 10.1007/s12541-015-0024-2

25. Seo H, Zheng C, Lim W, Cha SW et al (2011) Temperature prediction model of wet clutch in coupling. In: IEEE Vehicle Power and Propulsion Conference VPPC, Chicago, IL, USA, 06.09.2011-09.09.2011 IEEE,

26. Chen G, Jin Y (2012) Verfahren zur Bestimmung der Nasskupplungstemperatur. BR112013021491A2; CA2827879A1; CN103459876A; CN103459876B; EP2697531A1; EP2697531B1; MX2013011824A; WO2012142277A1; US2012261228A1; US8600636B2, April 12

27. Polifke W, Kopitz J (2009) Wärmeübertragung: Grundlagen, analytische und numerische Methoden, 2nd edn. Always learning. Pearson Studium, München u.a

28. Meingaßner GJ, Pflaum H, Stahl K (2015) Test-rig based evaluation of performance data of wet disk clutches. In: 14th International CTI Symposium

29. Stockinger U, Groetsch D, Pflaum H, Reiner F et al (2020) Friction behavior of innovative carbon friction linings for wet multi-plate clutches. Forsch Ingenieurwes. https://doi.org/10.1007/s10010020-00436-9

30. Voelkel K, Pflaum H, Stahl K (2019) Einflüsse der Stahllamelle auf das Einlaufverhalten von Lamellenkupplungen. Forsch Ingenieurwes 28(7):2148. https://doi.org/10.1007/s10010-019-00303-2

31. Voelkel K, Pflaum H, Stahl K (2020) Running-in behavior of wet multi-plate clutches: introduction of a new test method for investigation and characterization. Chin J Mech Eng 33(1):1461. https:// doi.org/10.1186/s10033-020-00450-6

32. Wohlleber F, Pflaum H, Höhn B-R, Stahl K (2011) Wärmeübergang Lamellenkupplung: Ermittlung von Wärmeübergangsverhalten und Schluckvermögen von Lamellenkupplungen. FVA-Nr. 413 II+III Heft 985. Forschungsvereinigung Antriebstechnik e. V., Frankfurt/ Main 